\title{
Role of fetal DNA in preeclampsia (Review)
}

\author{
BARBORA KONEČNÁ ${ }^{1}$, BARBORA VLKOVÁ ${ }^{1,2}$ and PETER CELEC ${ }^{1-4}$ \\ ${ }^{1}$ Institute of Molecular Biomedicine, Faculty of Medicine, Comenius University; ${ }^{2}$ Center for Molecular Medicine, \\ Slovak Academy of Sciences; ${ }^{3}$ Institute of Pathophysiology, Faculty of Medicine, ${ }^{4}$ Department of Molecular Biology, \\ Faculty of Natural Sciences, Comenius University, Bratislava, Slovakia
}

Received September 19, 2014; Accepted December 2, 2014

DOI: 10.3892/ijmm.2014.2039

\begin{abstract}
Preeclampsia is an autoimmune disorder characterized by hypertension. It begins with abnormal cytotrophoblast apoptosis, which leads to inflammation and an increase in the levels of anti-angiogenic factors followed by the disruption of the angiogenic status. Increased levels of fetal DNA and RNA coming from the placenta, one of the most commonly affected organs in pregnancies complicated by preeclampsia, have been found in pregnant women with the condition. However, it remains unknown as to whether this is a cause or a consequence of preeclampsia. Few studies have been carried out on preeclampsia in which an animal model of preeclampsia was induced by an injection of different types of DNA that are mimic fetal DNA and provoke inflammation through Toll-like receptor 9 (TLR9) or cyclic guanosine monophosphate-adenosine monophosphate (cGAMP). The specific mechanisms involved in the development of preeclampsia are not yet fully understood. It is hypothesized that the presence of different fragments of fetal DNA in maternal plasma may cause for the development of preeclampsia. The function of DNase during preeclampsia also remains unresolved. Studies have suggested that its activity is decreased or the DNA is protected against its effects. Further research is required to uncover the pathogenesis of preeclampsia and focus more on the condition of patients with the condition.
\end{abstract}

\section{Contents}

1. Preeclampsia as a series of disorders

2. Inflammation in preeclampsia

3. Role of fetal DNA in preeclampsia

4. Biology of fetal DNA

5. Causes and prevention of preeclampsia

6. Conclusions

Correspondence to: Barbora Konečná, Institute of Molecular Biomedicine, Comenius University, Sasinkova 4, SK-811 08 Bratislava, Slovakia

E-mail: basa.konecna@gmail.com

Key words: preeclampsia, fetal DNA, inflammation, angiogenesis, Toll-like receptor 9

\section{Preeclampsia as a series of disorders}

Preeclampsia belongs to the group of hypertensive disorders of pregnancy. It belongs to the same group of disorders, which also includes gestational hypertension and chronic hypertension. Preeclampsia is one of the complications of pregnancy responsible for maternal and perinatal morbidity and mortality (1), and is as life-threatening for the mother as it is for the fetus. Scientists and doctors have been unable to find a means of controling this disorder. The present review summarizes the facts that have been recently obtained from various studies, including studies on animals, which are based on the knowledge of the most experienced scientists. It discusses the most important results of previously published studies on preeclampsia, as well as the role of fetal DNA in the pathogenesis of this disorder.

Preeclampsia is most commonly classified into early-onset (before 34 weeks) and late-onset preeclampsia (after 34 weeks). Signs of early-onset preeclampsia include abnormal placentation, fetal growth restriction and the deterioration of maternal health, whereas late-onset preeclampsia is determined mostly by the symptoms observed in the mother only (2). In preeclampsia there is also reduced placental perfusion, which causes complications, such as the widespread apoptosis of cytotrophoblasts that invade the uterus (3).

Cytotrophoblasts are abnormally decayed as a result of the non-standard proliferation and differentiation due to maternal conditions (4). Most importantly, the reduced perfusion of the placenta affects the placenta itself. The preeclamptic placenta is light, thick and not as circular in shape as the placenta of a normal pregnancy. There is massive trophoblastic invasion in the center of the placenta, which decreases towards the periphery (5). Image analysis of histological sections of the preeclamptic placenta has shown enhanced villus bifurcation, huge syncytial knots and minor sclerotic villi (6). In a previous study using a mouse model of preeclampsia, visible differences were observed between the placentas from the mice with a normal pregnancy and those with hypertensive disorders (7).

Endothelial cell activation has been described to occur during preeclampsia (8). The altered synthesis and the release of endothelial cells initiate endothelial dysfunction along with the imbalance between vasodilation and vasoconstrictor prostaglandins (9). Initially, one of the functions of the endothelium is the generation of new vessels through the process of angiogenesis. Therefore, there is an imbalance between angiogenic and 
anti-angiogenic factors. The high activity of anti-angiogenic factors is one of the characteristics of preeclampsia (10). It has also been proven that normotensive women with preeclampsia tend to have increased blood pressure, sometimes even to a critical point. These women have been found to have high levels of protein in urine after 20 weeks of gestation when afflicted with preeclampsia (11). The high risk group includes women with chronic hypertension, diabetes mellitus, kidney disease and a high body mass index, as well as women of advanced maternal age (12).

It can be stated that preeclampsia can be classified as an autoimmune disease. It has been shown that the sera from preeclamptic women contain autoantibodies that react with angiotensin receptor 1 , which activate it and induce immune responses (13). In animal experiments, the administration of autoantibodies has been shown to cause high blood pressure, proteinuria and the production of soluble factors derived from the placenta (14). All the symptoms of preeclampsia mentioned above suggest that preeclampsia is a series of disorders, which manifest mainly during gestation.

\section{Inflammation in preeclampsia}

Inflammation is characterized as a non-specific response of an organism to various stimuli which affect all types of tissues (15). By activating neutrophils and macrophages, the initiation of acute inflammation is launched. By the infiltration of $\mathrm{T}$ lymphocytes and plasma cells, the inflammation becomes a non-self-limiting response and consequently becomes chronic inflammation.

Even though some crucial facts about preeclampsia are known, its etiology remains clear. One of the facts is that soluble fms-like tyrosine kinase 1 (sFlt-1) expression is increased during pregnancies complicated by preeclampsia (16). sFlt-1 is an anti-angiogenic protein that is produced by trophoblasts as a response to placental hypoxia. However, the main stimulus behind this activation remains unclear. It has been suggested that the activation of sFlt-1 occurs through platelet-monocyte aggregates, which are known to induce signaling pathways in monocytes and may be the cause for the release of interleukin (IL)-6, IL-8 and IL-1 $\beta$ (17). On the other hand, the secretion of sFlt-1 may be caused by other factors, such as the LIGHT factor, a novel tumor necrosis factor superfamily member, the growth level of which can be observed during preeclampsia; it may also be the cause of sFlt-1 secretion (18).

Angiogenic stability is secured by the balance between vascular endothelial growth factor (VEGF) and placental growth factor (PIGF), which are pro-angiogenic factors, and sFlt-1 and soluble endoglin (sEng), which are both antiangiogenic (19). In fact, VEGF and PIGF are produced by cytotrophoblasts and villous syncytiotrophoblasts in the placenta (20). It is known that during pregancies complicated by preeclampsia, the levels of VEGF and PIGF are reduced; this correlates with the higher levels of sFlt-1 (21). However, it is not clear as to whether this decrease is the cause or the consequence of the hither sFlt-1 levels. The ratio of VEGF to sFlt-1 has also been shown to be decreased in diseases associated with endothelial dysfunction, for example in diabetic retinopathy (22). VEGF polymorphisms, cooperating with other outer factors and genetics, play a crucial role in the incidence of HELLP syndrome, which occasionally occurs in connection with preeclampsia (23). The question is whether VEGF has any impact on the incidence of preeclampsia. A group of German researchers measured the sFlt-1/PlGF ratio in order to assess the clinical validity of preeclampsia. They found that this ratio is not a decisive factor in predicting preeclampsia, although it can be useful as an indicator of its severity along with other co-factors (24) (Fig. 1).

Furthermore, there are several studies focusing on which genes are expressed in preeclampsia, but the findings differ widely $(25,26)$. Within a single mesasurment, one can expect that some genes are upregulated whereas others are downregulated; however, the outcome varies from sample to sample (27). Kleinrouweler et al (28) published a review, the outcome of which was the identification of 33 eligible genes and their expression data in placental tissue in preeclampsia. Some of the transcripts encode proteins that may be potential biomarkers of the disease.

Not only gene expression but also the amount of antioxidants fluctuates between the same pathological samples, which leads to different levels of oxidative stress. The growth of oxidative stress products may be the result of reperfusion of the placenta and poor circulation in this organ. Under these conditions, ATP breaks down to substances which, when metabolized, produce reactive oxygen species, and the organism needs to use the stock of antioxidants to deactivate them (29). This shift in antioxidant status may affect signaling pathways (30). The gene expression levels are possibly affected by the degree of trophoblastic invasion of the placenta (27) or by the dysregulation of the trophoblastic gene expression itself. In spite of the knowledge of these facts, it should be emphasized again that the etiology of preeclampsia is not well known. Therefore, no causal therapy for preeclampsia has been established yet.

\section{Role of fetal DNA in preeclampsia}

In 1997, Lo et al (31) detected the presence of circulating fetal DNA in maternal plasma and serum. This finding offered a unique possibility of access to fetal material using a noninvasive method i.e., a regular blood test. Until this discovery, fetal genetic material was obtained through amniocentesis or chorionic villus sampling. Nowadays, several medical tests, such as testing for sex-linked disorders, can be performed more easily. The amount of fetal DNA increases as the delivery date approaches. Increased fetal DNA concentrations are closely associated with certain pregnancy disorders, most importantly with preeclampsia and trisomy 21 (32).

A number of studies have been carried out to show that the levels of fetal DNA are significantly higher in pregnancies complicated by preeclampsia in comparison with normal pregnancies. A group of researchers from Switzerland measured circulating DNA levels in samples from pregnant women with preeclampsia and women with normal pregnancy by realtime polymerase chain reaction, and showed that increased fetal DNA levels were associated with preeclampsia (33). Hahn et al (34) suggested that circulating fetal DNA levels can be used as a predicting factor of preeclampsia. As mentioned above, preeclampsia is considered an autoimmune disease. Based on this and the presence of fetal DNA in maternal plasma, Vlková et al (35) suggested that fetal RNA induces 


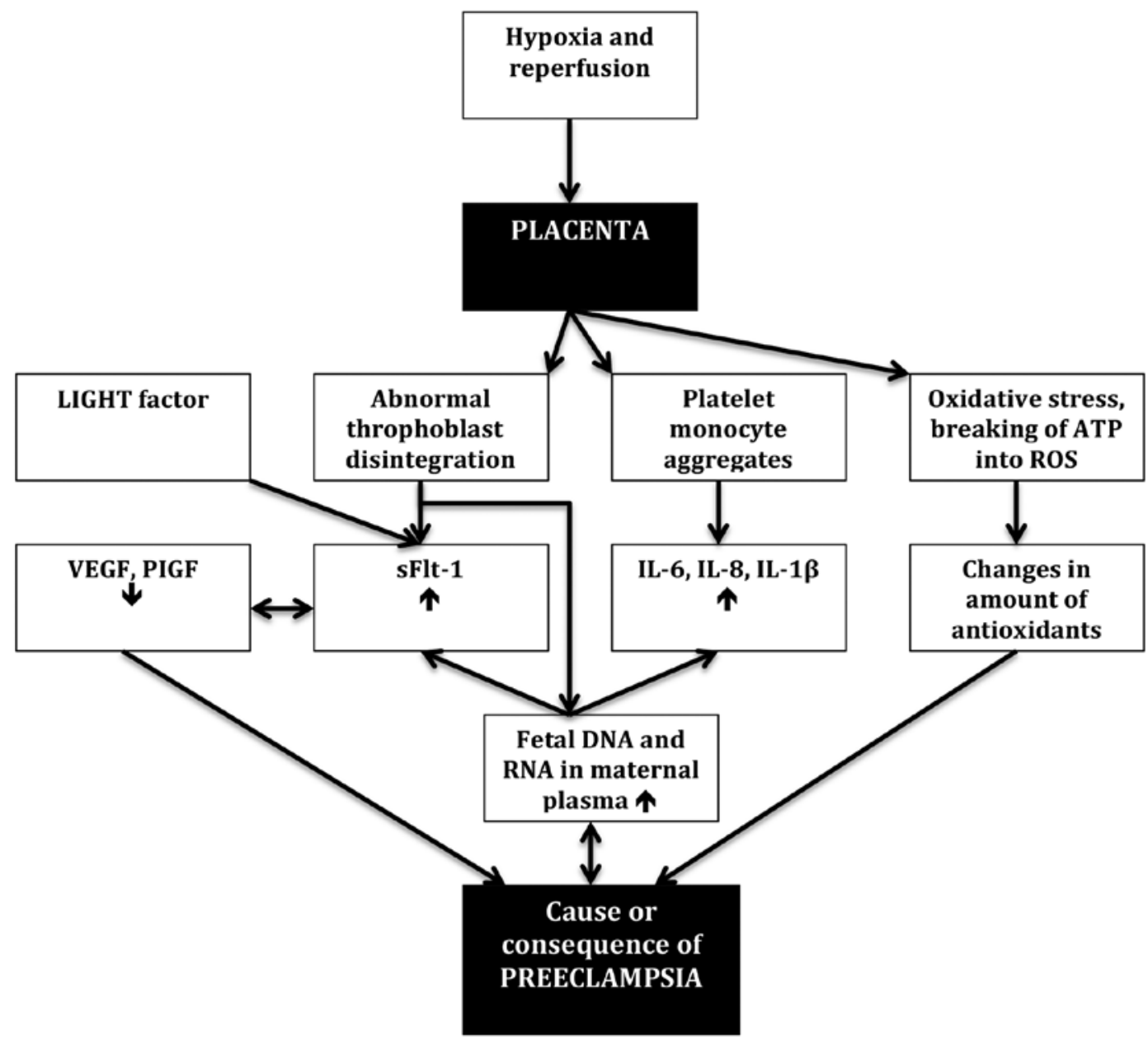

Figure 1. Changes in the levels of different factors in pregnancies complicated by preeclampsia.

an autoimmune reaction by directing the immune system of the mother against her own antigens by a complicated process of transfection of maternal monocytes with fetal fragments of RNA. On the whole, the ratio of fetal to maternal DNA in the plasma of the mother is very low. The most important contribution to non-invasive prenatal diagnosis was the establishment of real-time quantitative polymerase chain reaction, and the identification of specific fetal genes, rhesus D and $\mathrm{Y}$ chromosome $(36,37)$.

In addition to fetal DNA, other indicators of preeclampsia include angiogenic factors, soluble endoglin, P-selectin, pregnancy-associated plasma protein A, and so on. Despite numerous studies on preeclampsia, it remains unclear whether these are causes or consequences of preeclampsia (38). Realtime quantitative PCR has shown that fetal DNA in maternal plasma is hypomethylated before and after digestion by methylation-sensitive restriction enzymes (39). The placenta, in particular, was observed to contain a high percentage of methylated DNA in comparison with other tissues; therefore, the activity of DNA methyltransferase inhibitors results in small placentas and, as shown by a histological evaluation, the labyrinthine part of the placenta is also severely reduced in animal experiments (40). In 2010, Vora et al (41) made a correlation between cell-free fetal DNA and other factors indicating the placental condition. Lo et al (42) measured the levels of these factors using real-time PCR for DYS1 (multicopy $\mathrm{Y}$ chromosome sequence) and found that total and fetal DNA levels correlated with the results of the PAPP-A test in the first trimester of the pregnancy. However, there was no association between fetal DNA and other factors in the second trimester. Moreover, fetal DNA rapidly disappears from maternal plasma following delivery (42). Nevertheless, it is still not clear whether increased fetal DNA levels are the cause or consequence of preeclampsia. Scharfe-Nugent et al (43), who demonstrated that the injection of high concentrations of fetal DNA induces inflammation and symptoms similar to preeclampsia in mice, also discussed this issue. However, other factors may have affected the outcome observed in their study, and, thus, their conclusion was that the role of fetal DNA remains unclear. More specifically, the DNA used by Scharfe-Nugent et al (43) came from human tissue. Therefore, the outcome of their experiment may have been affected by the use of DNA from different species (i.e., using human DNA in mice).

\section{Biology of fetal DNA}

Cell-free DNA, and therefore extracellular and cytosolic DNA is recognized by cell receptors and induces cell reactions. As mentioned earlier, cell-free fetal DNA circulating freely in the maternal bloodstream is hypomethylated in preeclampsia. This 


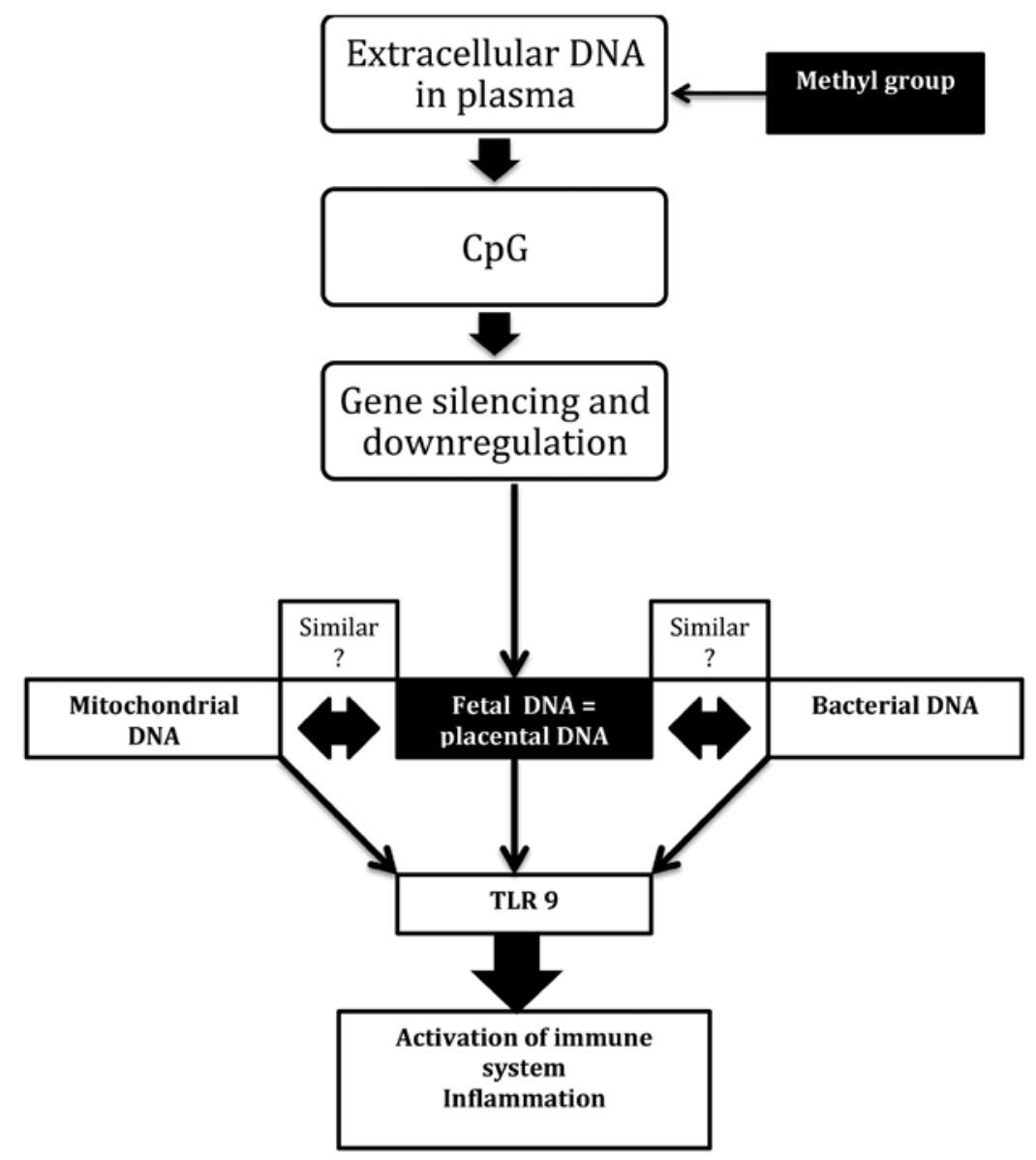

Figure 2. Hypomethylated fetal DNA in maternal plasma and the molecular pathway leading to inflammation.

means that the methyl group is added to the DNA molecule at the cytosine-guanine residue and forms the so-called $\mathrm{CpG}$. This addition has such an effect that it blocks transcription factors followed by gene silencing and downregulation $(44,56)$. Furthermore, the increased apoptosis of trophoblasts in placentas from pregnancies complicated by preeclampsia produces circulating fetal DNA containing mitochondrial DNA (mtDNA) (45). Toll-like receptors (TLRs) are sensitive to this type of molecule in the way that they are sensitive to bacterial or viral ones. The reason is that mtDNA is structurally similar to bacterial DNA and covers $\mathrm{CpG}$ sides as well. Consequently, after sensing these molecules, the TLR9 receptor activates the immune system and initiates inflammation $(46,47)$ (Fig. 2).

Sepsis, i.e., the systemic inflammatory response syndrome secondary to bacterial infection (48), is associated with mtDNA. Mitochondrial dysfunction plays a crucial role in the pathogenesis of sepsis. Reactive oxygen species and reactive nitrogen species may cause the dysfunction of several organelles, such as mitochondria, and inflict inflammation (49). Jiménez-Sousa et al (50) studied the potential association between mtDNA and severe sepsis and found that different mitochondrial haplogroups affected the development of sepsis.

Under certain circumstances, tumor necrosis factor- $\alpha$ (TNF- $\alpha$ ) and lipopolysaccharides stimulate cellular cyclic guanosine monophosphate-adenosine monophosphate (cGAMP), which is responsible for DNA synthesis (51). In pregnancies complicated by preeclampsia, the growth of
cGAMP is the result of high levels of circulating natriuretic peptides $(52,53)$. When cytosolic DNA is transfected, cGAMP is triggered and binds to the endoplasmic-reticulum-resident protein STING, followed by the activation of interferon 3 and interferon $\beta$ (54). Yet, cGAMP produces a nucleotide second messenger and belongs to the family of oligoadenylate synthetases, which can produce unique 2'-5'-phosphodiester bonds (55). Taking into account all of the above, it can be hypothesized that circulating fetal DNA in pregnancies complicated by preeclampsia behave in a similar manner to bacterial DNA or mtDNA, and may thus activate cGAMP and induce inflammation. If this is the case, then fetal DNA is one of the possible causes of preeclampsia.

\section{Causes and prevention of preeclampsia}

Due to the increasing number of cases of pre-term births and the danger this poses by causing life-long handicaps, a number of studies have focused on determining the causes of and finding a solution to this issue. The association between fetal DNA and preterm birth in pregnancies complicated by preeclampsia has already been demonstrated by an Irish research group who demonstrated, through animal experiments, that circulating free DNA induces inflammation, leading to pre-term delivery (43). Their study was based on injecting either human fetal DNA or $\mathrm{CpG}$ into mice. The authors suggested that the TLR9 receptor detects hypomethylated fetal DNA 
and provokes inflammation, leading to preeclampsia (43). Their outcome was that the application of human fetal DNA infiltrated in the placenta induced inflammation in pregnant mice, causing fetal resorption and pre-term delivery. Either way, the pregnancy status is closely associated with TLR9. When both human fetal DNA and TLR9 inhibitor chloroquine were injected into mice, the pregnancies had a better outcome. Chloroquine is known to cross the placenta when applied; thus, its metabolites have been found in the urine of neonates delivered from mothers treated with this medication (57). In conclusion, Scharfe-Nugent et al (43) reported the impact of human fetal DNA on mouse fetuses and their delivery status only. However, information on the impact on the mothers and basic preeclampsia parameters, such as blood pressure and proteinuria was not provided. Moreover, it should also be noted that interspecies differences may affect the induction of an immune response similar to that induced by bacterial DNA.

\section{Conclusions}

The majority of available evidence suggests that fetal DNA is either the cause or a consequence of preeclampsia. As already mentioned, in a previous study, Lo et al (31) demonstrated that fetal DNA was significantly increased in maternal plasma in preeclamptic patients; thus, the possibility of prenatal diagnosis was no longer a doubt for patients. In comparison with the past, when acquiring fetal material was an invasive intervention (through amniocentesis or chorionic villi sampling), today fetal material can be obtained safely through the collection of maternal blood. Moreover, it has been demostrated that the levels of fragmentation of fetal DNA are different in maternal plasma (58). As previously demonstrated, short fragments of fetal DNA are more suitable for PCR amplification and further prenatal analysis (58). Overall, the diagnosis has focused on the detection of Down syndrome and other fetal chromosomal aneuploidies (59), single gene disorders which are paternally inherited, and on simply decoding the fetal genome for various purposes. However, due to the increasing incidence of preeclampsia cases associated with conditions, such as inherited hypertension and obesity, prenatal diagnosis now also focuses on the prevention of preeclampsia.

The issue of whether preeclampsia can be prevented in pregnant women remains unresloved. One of the assumptions is that in pregnancies complicated by preeclampsia, DNase activity is lowered due to inflammation. An alternative suggestion is that the function of DNase is normal, but fetal DNA are somehow protected from its lytic activity. After delivery, circulating DNA is cleared from the maternal plasma rapidly (42). However, the exact mechanisms involved are not clear. Certain studies have reported the use of magnesium sulphate in preeclampsia and that its application was effective in the management of severe preeclampsia in terms of seizure prevention (60-62); however, it is not always effective. Another possibility is the use of chloroquine, which may act as a TLR9 inhibitor. as demonstrated by Scharfe-Nugent et al (43).

Further research is required in order to determine the principal cause of preeclampsia and the role of fetal DNA in its pathogenesis, as well as the ways that the condition can be prevented. Most importantly, more studies should be directed towards the overall health throughout the gestational period.

\section{Acknowledgements}

The present study was supported by the Slovak Research and Development Agency under contract APVV-0754_10.

\section{References}

1. Steegers EA, von Dadelszen P, Duvekot JJ and Pijnenborg R: Pre-eclampsia. Lancet 376: 631-644, 2010.

2. Trogstad L, Magnus P and Stoltenberg C: Pre-eclampsia: Risk factors and causal models. Best Pract Res Clin Obstet Gynaecol 25: 329-342, 2011.

3. Genbacev O, DiFederico E, McMaster M and Fisher SJ: Invasive cytotrophoblast apoptosis in pre-eclampsia. Hum Reprod 14 (Suppl 2): S59-S66, 1999.

4. Roberts JM and Escudero C: The placenta in preeclampsia. Pregnancy Hypertens 2: 72-83, 2012.

5. Kajantie E, Thornburg KL, Eriksson JG, Osmond C and Barker DJ: In preeclampsia, the placenta grows slowly along its minor axis. Int J Dev Biol 54: 469-473, 2010.

6. Roberts DJ and Post MD: The placenta in pre-eclampsia and intrauterine growth restriction. J Clin Pathol 61: 1254-1260, 2008.

7. Ma RQ, Sun MN and Yang Z: Effects of preeclampsia-like symptoms at early gestational stage on feto-placental outcomes in a mouse model. Chin Med J (Engl) 123: 707-712, 2010.

8. Roberts JM: Endothelial dysfunction in preeclampsia. Semin Reprod Endocrinol 16: 5-15, 1998.

9. Mustafa R, Ahmed S, Gupta A and Venuto RC: A comprehensive review of hypertension in pregnancy. J Pregnancy 2012: 105918 , 2012.

10. Escudero C, Roberts JM, Myatt L and Feoktistov I: Impaired adenosine-mediated angiogenesis in preeclampsia: potential implications for fetal programming. Front Pharmacol 5: 134, 2014.

11. Sibai BM: Maternal and uteroplacental hemodynamics for the classification and prediction of preeclampsia. Hypertension 52: 805-806, 2008.

12. Duckitt K and Harrington D: Risk factors for pre-eclampsia at antenatal booking: systematic review of controlled studies. BMJ 330: 565, 2005.

13. Wallukat G, Homuth V, Fischer T, Lindschau C, Horstkamp B, Jüpner A, Baur E, Nissen E, Vetter K, Neichel D, Dudenhausen JW, Haller H and Luft FC: Patients with preeclampsia develop agonistic autoantibodies against the angiotensin AT1 receptor. J Clin Invest 103: 945-952, 1999.

14. Zhou CC, Ahmad S, Mi T, Abbasi S, Xia L, Day MC, Ramin SM, Ahmed A, Kellems RE and Xia Y: Autoantibody from women with preeclampsia induces soluble Fms-like tyrosine kinase-1 production via angiotensin type 1 receptor and calcineurin/nuclear factor of activated T-cells signaling. Hypertension 51: 1010-1019, 2008.

15. Ferrero-Miliani L, Nielsen $\mathrm{OH}$, Andersen PS and Girardin SE: Chronic inflammation: importance of NOD2 and NALP3 in interleukin-1beta generation. Clin Exp Immunol 147: 227-235, 2007.

16. Levine RJ, Maynard SE, Qian C, Lim KH, England LJ, Yu KF, Schisterman EF, Thadhani R, Sachs BP, Epstein FH, Sibai BM, Sukhatme VP and Karumanchi SA: Circulating angiogenic factors and the risk of preeclampsia. N Engl J Med 350: 672-683, 2004.

17. Major HD, Campbell RA, Silver RM, Branch DW and Weyrich AS: Synthesis of sFlt-1 by platelet-monocyte aggregates contributes to the pathogenesis of preeclampsia. Am J Obstet Gynecol 210: 547.e541-e547, 2014.

18. Wang W, Parchim NF, Iriyama T, Luo R, Zhao C, Liu C, Irani RA, Zhang W, Ning C, Zhang Y, Blackwell SC, Chen L, Tao L, Hicks MJ, Kellems RE and Xia Y: Excess LIGHT contributes to placental impairment, increased secretion of vasoactive factors, hypertension, and proteinuria in preeclampsia. Hypertension 63: 595-606, 2014.

19. Ehrig JC, Horvat D, Allen SR, Jones RO, Kuehl TJ and Uddin MN: Cardiotonic steroids induce anti-angiogenic and anti-proliferative profiles in first trimester extravillous cytotrophoblast cells. Placenta 35: 932-936, 2014.

20. Weed S, Bastek JA, Anton L, Elovitz MA, Parry S and Srinivas SK: Examining the correlation between placental and serum placenta growth factor in preeclampsia. Am J Obstet Gynecol 207: 140.e141-e146, 2012. 
21. Bills VL, Varet J, Millar A, Harper SJ, Soothill PW and Bates DO: Failure to up-regulate VEGF165b in maternal plasma is a first trimester predictive marker for pre-eclampsia. Clin Sci (Lond) 116: 265-272, 2009

22. Zhai YL, Zhu L, Shi SF, Liu LJ, Lv JC and Zhang H: Elevated soluble VEGF receptor sFlt-1 correlates with endothelial injury in IgA nephropathy. PLoS One 9: e101779, 2014.

23. Haram K, Mortensen JH and Nagy B: Genetic aspects of preeclampsia and the HELLP syndrome. J Pregnancy 2014: 910751, 2014

24. Lehnen H, Mosblech N, Reineke T, Puchooa A, Menke-Möllers I, Zechner U and Gembruch U: Prenatal clinical assessment of sFlt-1 (soluble fms-like tyrosine kinase-1)/PlGF (placental growth factor) ratio as a diagnostic tool for preeclampsia pregnancy-induced hypertension, and proteinuria. Geburtshilfe Frauenheilkd 73: 440-445, 2013.

25. Sitras V, Paulssen RH, Gronaas H, Leirvik J, Hanssen TA, Vartun A and Acharya G: Differential placental gene expression in severe preeclampsia. Placenta 30: 424-433, 2009.

26. Reimer T, Koczan D, Gerber B, Richter D, Thiesen HJ and Friese K Microarray analysis of differentially expressed genes in placental tissue of pre-eclampsia: up-regulation of obesity-related genes. Mol Hum Reprod 8: 674-680, 2002.

27. Ma K, Lian Y, Zhou S, Hu R, Xiong Y, Ting P, Xiong Y, Li X and Wang X: Microarray analysis of differentially expressed genes in preeclamptic and normal placental tissues. Clin Exp Obstet Gynecol 41: 261-271, 2014.

28. Kleinrouweler CE, van Uitert M, Moerland PD, Ris-Stalpers C, van der Post JA and Afink GB: Differentially expressed genes in the pre-eclamptic placenta: a systematic review and meta-analysis. PLoS One 8: e68991, 2013.

29. Roberts JM and Hubel CA: Oxidative stress in preeclampsia. Am J Obstet Gynecol 190: 1177-1178, 2004.

30. Bilodeau JF: Review: maternal and placental antioxidant response to preeclampsia - impact on vasoactive eicosanoids. Placenta 35 (Suppl): S32-S38, 2014.

31. Lo YM, Corbetta N, Chamberlain PF, Rai V, Sargent IL, Redman CW and Wainscoat JS: Presence of fetal DNA in maternal plasma and serum. Lancet 350: 485-487, 1997.

32. Lo YM: Fetal DNA in maternal plasma. Ann NY Acad Sci 906 141-147, 2000.

33. Zhong XY, Laivuori H, Livingston JC, Ylikorkala O, Sibai BM, Holzgreve W and Hahn S: Elevation of both maternal and fetal extracellular circulating deoxyribonucleic acid concentrations in the plasma of pregnant women with preeclampsia. Am J Obstet Gynecol 184: 414-419, 2001.

34. Hahn S, Rusterholz C, Hösli I and Lapaire O: Cell-free nucleic acids as potential markers for preeclampsia. Placenta 32 (Suppl): S17-S20, 2011

35. Vlková B, Szemes T, Minarik G, Turna J and Celec P: Circulating free fetal nucleic acids in maternal plasma and preeclampsia. Med Hypotheses 74: 1030-1032, 2010.

36. Yu H, Shen Y, Ge Q, He Y, Qiao D, Ren M and Zhang J: Quantification of maternal serum cell-free fetal DNA in early-onset preeclampsia. Int J Mol Sci 14: 7571-7582, 2013.

37. Chiu RW and Lo YM: Clinical applications of maternal plasma fetal DNA analysis: translating the fruits of 15 years of research. Clin Chem Lab Med 51: 197-204, 2013.

38. Grill S, Rusterholz C, Zanetti-Dällenbach R, Tercanli S, Holzgreve W, Hahn S and Lapaire O: Potential markers of preeclampsia - a review. Reprod Biol Endocrinol 7: 70, 2009.

39. Kim MJ, Kim SY, Park SY, Ahn HK, Chung JH and Ryu HM: Association of fetal-derived hypermethylated RASSF1A concentration in placenta-mediated pregnancy complications. Placenta 34: 57-61, 2013.

40. Koukoura O, Sifakis S and Spandidos DA: DNA methylation in the human placenta and fetal growth (review). Mol Med Rep 5: 883-889, 2012

41. Vora NL, Johnson KL, Lambert-Messerlian G, Tighiouart H, Peter I, Urato AC and Bianchi DW: Relationships between cell-free DNA and serum analytes in the first and second trimesters of pregnancy. Obstet Gynecol 116: 673-678, 2010.

42. Lo YM, Zhang J, Leung TN, Lau TK, Chang AM and Hjelm NM Rapid clearance of fetal DNA from maternal plasma. Am J Hum Genet 64: 218-224, 1999.

43. Scharfe-Nugent A, Corr SC, Carpenter SB, Keogh L, Doyle B, Martin C, Fitzgerald KA, Daly S, O'Leary JJ and O'Neill LA: TLR9 provokes inflammation in response to fetal DNA: mechanism for fetal loss in preterm birth and preeclampsia. J Immunol 188: 5706-5712, 2012.
44. Tost J: DNA methylation: an introduction to the biology and the disease-associated changes of a promising biomarker. Mol Biotechnol 44: 71-81, 2010.

45. Colleoni F, Lattuada D, Garretto A, Massari M, Mandò C, Somigliana E and Cetin I: Maternal blood mitochondrial DNA content during normal and intrauterine growth restricted (IUGR) pregnancy. Am J Obstet Gynecol 203: 365.e361-e366, 2010.

46. Zhang Q, Raoof M, Chen Y, Sumi Y, Sursal T, Junger W, Brohi K, Itagaki $\mathrm{K}$ and Hauser CJ: Circulating mitochondrial DAMPs cause inflammatory responses to injury. Nature 464: 104-107, 2010.

47. Goulopoulou S, Matsumoto T, Bomfim GF and Webb RC: Toll-like receptor 9 activation: a novel mechanism linking placenta-derived mitochondrial DNA and vascular dysfunction in pre-eclampsia. Clin Sci (Lond) 123: 429-435, 2012.

48. Levy MM, Fink MP, Marshall JC, Abraham E, Angus D, Cook D, Cohen J, Opal SM, Vincent JL and Ramsay G: 2001 SCCM/ESICM/ACCP/ATS/SIS International Sepsis Definitions Conference. Crit Care Med 31: 1250-1256, 2003.

49. Garrabou G, Morén C, López S, Tobías E, Cardellach F, Miró O and Casademont J: The effects of sepsis on mitochondria. J Infect Dis 205: 392-400, 2012.

50. Jiménez-Sousa MA, Tamayo E, Guzmán-Fulgencio $M$, Heredia M, Fernández-Rodríguez A, Gómez E, Almansa R, Gómez-Herreras JI, García-Âlvarez M, Gutiérrez-Junco S, Bermejo-Martin JF and Resino S; the Spanish Sepsis Group $(\mathrm{SpSG})$ : Mitochondrial DNA haplogroups are associated with severe sepsis and mortality in patients who underwent major surgery. J Infect: Jul 17, 2014 (Epub ahead of print). doi: 10.1016/j. jinf.2014.07.005.

51. Tantini B, Flamigni F, Pignatti C, Stefanelli C, Fattori M, Facchini A, Giordano E, Clô C and Caldarera CM: Polyamines, NO and cGMP mediate stimulation of DNA synthesis by tumor necrosis factor and lipopolysaccharide in chick embryo cardiomyocytes. Cardiovasc Res 49: 408-416, 2001.

52. Sandrim VC, Palei AC, Sertório JT, Amaral LM, Cavalli RC and Tanus-Santos JE: Alterations in cyclic GMP levels in preeclampsia may reflect increased B-type natriuretic peptide levels and not impaired nitric oxide activity. Clin Biochem 44: 1012-1014, 2011.

53. Okuno S, Hamada H, Yasuoka M, Watanabe H, Fujiki Y, Yamada N, Sohda S and Kubo T: Brain natriuretic peptide (BNP) and cyclic guanosine monophosphate (cGMP) levels in normal pregnancy and preeclampsia. J Obstet Gynaecol Res 25: 407-410, 1999.

54. Wu J, Sun L, Chen X, Du F, Shi H, Chen C and Chen ZJ: Cyclic GMP-AMP is an endogenous second messenger in innate immune signaling by cytosolic DNA. Science 339: 826-830, 2013.

55. Ablasser A, Goldeck M, Cavlar T, Deimling T, Witte G, Röhl I, Hopfner KP, Ludwig J and Hornung V: cGAS produces a 2'-5'linked cyclic dinucleotide second messenger that activates STING. Nature 498: 380-384, 2013.

56. Yuen RK, Peñaherrera MS, von Dadelszen $P$, McFadden DE and Robinson WP: DNA methylation profiling of human placentas reveals promoter hypomethylation of multiple genes in early-onset preeclampsia. Eur J Hum Genet 18: 1006-1012, 2010.

57. Essien EE and Afamefuna GC: Chloroquine and its metabolites in human cord blood, neonatal blood, and urine after maternal medication. Clin Chem 28: 1148-1152, 1982.

58. Koide K, Sekizawa A, Iwasaki M, Matsuoka R, Honma S, Farina A, Saito H and Okai T: Fragmentation of cell-free fetal DNA in plasma and urine of pregnant women. Prenat Diagn 25: 604-607, 2005

59. Evans MI and Kilpatrick M: Noninvasive prenatal diagnosis: 2010. Clin Lab Med 30: 655-665, 2010.

60. Kassie GM, Negussie D and Ahmed JH: Maternal outcomes of magnesium sulphate and diazepam use in women with severe preeclampsia and eclampsia in Ethiopia. Pharm Pract (Granada) 12: 400, 2014

61. Tannirandorn Y: Is magnesium sulfate for prevention or only therapeutic in preeclampsia? J Med Assoc Thai 88: 1003-1010, 2005.

62. von Dadelszen P and LA Magee: Pre-eclampsia:an update. Curr Hypertens Rep 16: 454, 2014. 